\title{
3. Inadequate response to frequency of payments in contingent valuation of environmental goods
}

\author{
Kelley Myers, George Parsons, and \\ Kenneth Train ${ }^{1}$
}

\section{INTRODUCTION}

The purpose of this chapter is to test the sensitivity of a willingness to pay (WTP) derived from a referendum-style contingent valuation (CV) survey to the frequency of payments specified in the valuation question. Using a split-sample survey we consider a one-time payment versus an annual reoccurring payment under the null hypothesis that the present values from the two payment frequencies will be the same. We offer this as a simple test of the validity of the $\mathrm{CV}$ method. In principle, one would hope that values are invariant with respect to frequency of payment. Boyle (forthcoming) notes that " $[t]$ his is another area where there is scant research" and cites some evidence that suggests respondents may fail to seriously consider the time frame of payments in the valuation question.

The setting for our analysis is the valuation of a conservation program designed to protect a migratory shorebird that has recently been in decline. We redesigned a survey previously used by Myers (2013) and Parsons and Myers (2016) to conduct our test. The split-sample surveys are identical but for the frequency of payment required - one uses one-time payment, the other uses annual reoccurring payment. With response data from both surveys, we estimate willingness to pay using a non-parametric Turnbull estimator and a parametric probit estimator and test for differences in willingness to pay between our treatments. We also consider sensitivity tests - weighting to align data with the census, adjustments for certainty of response, and adjustment for disbelief in bid amount.

1 Respectively: Senior Economist, Cardno, Newark, DE; Professor, School of Marine Science \& Policy and Department of Economics, University of Delaware; Adjunct Professor Emeritus, University of California, Berkeley. 
For the non-parametric and parametric measures, and across all our sensitivity analyses, we reject the null hypothesis that the present value of the willingness to pay from the one-time payment and reoccurring annual payment are equal. Indeed, respondents more or less treat the one-time payment and reoccurring annual payments as the same, which implies a present value for the annual payments that is about 30 times larger than for one-time payment. The implied discount rates, depending on the estimation method, range from 300 to $900 \%$.

Our results contribute to a small but growing literature that shows that $\mathrm{CV}$ estimates of willingness to pay are highly sensitive to the time frame of payment that is specified to respondents. The next section examines that literature before we present a discussion of our survey and results.

\section{LITERATURE REVIEW}

To our knowledge, six studies have compared CV estimates under annual versus one-time payments using a split-sample design (Table 1). In all six, the present value of respondents' willingness to pay (PV WTP) was estimated to be far higher when the cost prompts were stated as annual payments over a period of time than when the cost prompts were a one-time payment. Stated equivalently, the implicit discount rate that reconciles the responses under the two types of cost prompts was found to be implausibly high in all six studies.

Table 1 Implicit discount rates comparing one-time versus annual payments

\begin{tabular}{|c|c|c|c|}
\hline Authors & Resource & $\begin{array}{l}\text { Duration of } \\
\text { Payments }\end{array}$ & $\begin{array}{l}\text { Discount } \\
\text { Rate (\%) }\end{array}$ \\
\hline $\begin{array}{l}\text { Kahneman and } \\
\text { Knetsch (1992) }\end{array}$ & $\begin{array}{l}\text { Toxic waste treatment } \\
\text { facility }\end{array}$ & Five years & $130+$ \\
\hline $\begin{array}{l}\text { Echeverria et al. } \\
\text { (1995) }\end{array}$ & Forest preservation & In perpetuity & 559 \\
\hline Stevens et al. (1997) & $\begin{array}{l}\text { Atlantic salmon } \\
\text { restoration }\end{array}$ & Five years & 270 \\
\hline Bond et al. (2009) & Sea lion protection & $\begin{array}{l}\text { Five years } \\
\text { Fifteen }\end{array}$ & $\begin{array}{r}1,315 \\
61\end{array}$ \\
\hline $\begin{array}{l}\text { Kim and Haab } \\
\text { (2009) }\end{array}$ & Oyster reef restoration & $\begin{array}{l}\text { Duration of project } \\
\text { In perpetuity }\end{array}$ & $\begin{array}{r}98-131 \\
45\end{array}$ \\
\hline \multirow[t]{2}{*}{ Egan et al. (2015) } & $\begin{array}{l}\text { Wetlands protection for } \\
\text { beachgoers }\end{array}$ & Ten years & 104 \\
\hline & & In perpetuity & 62 \\
\hline
\end{tabular}


Kahneman and Knetsch (1992) compared respondents' stated WTP for a toxic waste treatment facility by a one-time payment versus annual payments for five years. The mean WTP was estimated to be $\$ 141$ when respondents were asked about a one-time payment, and $\$ 81$ annually when asked about annual payments for five years, which implies a discount rate of $130 \%$. When seven respondents (out of 206) with unreasonably large stated WTPs were eliminated, the results became even more extreme. The authors concluded that " $[\mathrm{t}]$ he results provide no reliable indication that the respondents discriminated between payment schedules that differed greatly in total present value."

Echeverria et al. (1995) examined WTP to prevent a forest preserve from being converted to agricultural use and stated that "no plausible discount rate equates [their finding of] a recurring annual annuity of $\$ 110.64$ to a single lump sum net present value of $\$ 130.43$." The implicit discount rate is $559 \%{ }^{2}$

Stevens et al. (1997) examined restoration of Atlantic salmon and found that respondents have a mean WTP of $\$ 21.20$ annually for five years, which has a present value (PV) of $\$ 96.37$ at a $5 \%$ discount rate, versus a lump-sum mean WTP of $\$ 29.00 .^{3}$ That is, the mean PV WTP is estimated to be more than three times greater when the cost prompt is stated as annual payments for five years rather than a lump-sum payment. The implicit discount rate is $270 \%{ }^{4}$ The authors state that, "[i]nsensitivity to payment schedule may therefore be an important, but often overlooked factor in the design, interpretation, and use of contingent valuation studies."

Bond et al. (2009) examined WTP for measures that protect the Western stock of the Stellar sea lion in Alaska using three payment mechanisms that differed in duration. Some respondents considered the protection measures hurtful (negative WTP) and others as helpful (positive WTP), and to account for this difference, the authors segmented the sample on the basis of exogenous factors that partially differentiated the two groups. For the group that tended to have a positive WTP, the authors report a PV WTP of $\$ 208.78$ based on a one-time payment, $\$ 874.38$ based on

2 The present value of annuity that starts immediately is $X(1+r) / r$ where $X$ is the annual payment and $r$ the discount rate. The value of $r$ that equates $130.43=110.64(1+r) / r$ is $r=$ 5.59. The same $r$ is obtained when the payments are assumed to start at the end of the current year.

3 The PV calculation assumes that the payments begin immediately. If the lump-sum and first annual payment are made at the end of the year, then each PV is lower by $1 /(1.05)$, but the ratio of PVs and the implicit discount rate are the same.

42.7 is the value of $r$ that equates $29=21.2 *\left(1+(1+r)^{-1}+(1+r)^{-2}+(1+r)^{-3}+(1+\right.$ $\left.r)^{-4}\right)$. In parametric models with different specifications, the authors report that the estimated discount rate "ranged from 50 to $270 \%$." 
annual payments for five years, and $\$ 886.72$ based on annual payments for 15 years, using a discount rate of $5.49 \% .^{5}$ That is: changing the payment plan in the survey from a one-time payment to annual payments raised the estimated PV WTP by a factor of over four. The implicit discount rate is $1,315 \%$ (no, that is not a typo) for the five-year plan compared to the one-year plan, $61 \%$ for the 15 -year plan compared to the one-year plan, and $5.85 \%$ for the 15 -year plan compared to the five-year plan. ${ }^{6}$ The high implicit discount rates arose in this study when comparing the one-time payment with a stream of payments over time, and not when comparing streams of different lengths. ${ }^{7}$

Kim and Haab (2009) study oyster reef restoration using a variety of project lengths (five and ten years) and different payment schemes: onetime payment, annual payment over the life of the project, and annual payment in perpetuity. For the comparison of one-time versus annual payments for the duration of the project, discount rates were estimated to be $98-131 \%$. A relatively low rate of $45 \%$ was obtained in the comparison of one-time payments against annual payments in perpetuity. ${ }^{8}$

Egan et al. (2015) estimated WTP by beachgoers on beaches on Lake Erie to preserve a nearby wetland that would, in turn, improve water quality and other environmental conditions where people swim and enjoy the park. They considered one-time, ten-year annual and perpetual payments. They compared their results to a travel cost model. Their PV WTP

5 The authors reported that $5.49 \%$ was the 30 -year bond yield at the time.

6 With payments that start immediately and $r=0.0549,194.05$ is the value of $X$ that equates $874.38=X^{*}\left(1+(1+r)^{-1}+(1+r)^{-2}+(1+r)^{-3}+(1+r)^{-4}\right)$. Then the implicit discount rate at which the PV of the one-year payment of 208.78 equals that of five-year payments of 194.05 apiece is the $r$ at which $208.78=194.05^{*}\left(1+(1+r)^{-1}+(1+r)^{-2}+(1+r)^{-3}\right.$ $\left.+(1+r)^{-4}\right)$, which is $r=13.15$. Similar calculations provide the implicit discount rates for the other plan comparisons. Note that the same value of $r$ is obtained if payments are assumed to start at the end of the current year.

7 Using parametric models, the authors estimated a discount rate of $23 \%$ when all payment plans were pooled and $80 \%$ when the one- and 15 -year plans were pooled. The $80 \%$ corresponds to the $61 \%$ given above from direct estimation. The lower discount rate for all three plans combined is apparently due to the comparatively low discount rate implicit in the five- and 15-year comparison. The authors did not report a parametric estimate of discount rate for the one- and five-year plans combined.

8 The abstract to the Kim and Haab (2009) study says that "the temporal willingness to pay for the project is the same across different payment schemes," which can be confusing to people who have not read the full article. The authors tested whether the non-cost coefficients of a probit model were the same under different payment schemes, allowing the cost coefficient to differ by payment scheme. The hypothesis of no difference in non-cost coefficients was accepted, with the estimated cost coefficient differing over payment schedules. The noncost terms in utility capture the benefits of the program, which is the basis of the authors' statement in the abstract. The PV WTP, which is the utility benefits divided by the coefficient of PV costs, differed considerably over payment schemes, as the authors show by their calculation of the discount rates that we give in the text above. 
estimates are $\$ 45, \$ 185$, and $\$ 360$ for one-time, ten-year annual, and perpetual annual payments using a $5 \%$ discount rate. The implied discount rates for the one-time payment is $104 \%$ when compared to the ten-year annual payments and $62 \%$ when compared to the perpetual annual payments. The implied rate for ten-year annual payments when compared with perpetual payments is $15 \%$. Egan et al. (2015) go on to argue that perpetual annual payments are preferred because their estimated values (at least in their application) are closest to the travel cost estimates and in their judgment people are unlikely to be able to do the discounting implicitly required in a one-time payment option.

In addition to these six studies, five other studies have conducted analyses that shed light on $\mathrm{CV}$ estimates under different payment horizons, but were not comparing annual versus lump-sum payments. All of these studies found that CV estimates differ greatly depending on how the payment question is formulated. The five studies are the following.

Rowe et al. (1992) compared two ways of describing a five-year payment schedule. The authors asked one group of respondents how much they were WTP annually for five years, and asked another group of respondents how much they were WTP in total over five years. If the latter group considered the payments to be evenly spaced over the five years, then the two groups were considering the same payment schedule. However, if the latter group thought that the payments would not be evenly spaced (e.g., occurring more up front, or more later), then the two schedules differ. In any case, the authors found that total WTP over the five years was considerably higher for the first group (who were asked WTP annually for five years) than for the second group (who were asked total WTP over five years).

Solino et al. (2009) conducted a similar comparison of two different ways of paying the same total amount: "In one [version of the survey] we considered an annual payment and in the other a bimonthly payment, with equivalent aggregated monetary amounts." Their cost prompts were $€ 5-20$ bimonthly in one survey and €60-120 annually in the other. The total amount paid in each year was the same under both sets of prompts, with just the periodicity differing. Consistent with Rowe et al. (1992), Solino et al. (2009) found more favorable response for smaller but more frequent payments even when the total amount of payment was the same: "[W]e observe that $76.87 \%$ [of respondents] replied affirmatively to the valuation question in the bimonthly version, while in the annual version this percentage drops to $67.27 \%$."

Stumberg et al. (2001) compared three-year and ten-year annual payment schedules. Using a split-sample design, they found that "payment time horizon has a significant effect on valuation statements," with the PV WTP 
being far greater when based on the ten-year scheme than the three-year scheme. ${ }^{9}$

Kovacs and Larson (2008) examined monthly payments for one, four, seven, and ten years. They report estimated discount rates of "around $30 \%$." However, the authors' estimates were obtained from models that included responses to follow-up questions (double-bounded data) and a variety of adjustments for potential behavioral issues. Direct examination of their data indicates that the discount rate implied by their study is actually over $85 \%$. In particular: the one-year and four-year plans were designed to have the same present value at a discount rate of $85 \%$. However, more respondents said "yes" to the four-year plan than the one-year plan, which means that the implicit discount rate exceeds $85 \%$. Similarly, high discount rates arise for the seven- and ten-year plans compared to the one-year plan.

Chen et al. (2014) employed an internal comparison of one-time versus annual payments (as opposed to using split samples) by asking each respondent their WTP under both schedules and allowing them to go back and change their answer for one schedule after considering the other schedule. This procedure tests the internal consistency of respondents' answers to both schedules. The authors report that "the LBM [lower bound mean] estimated was $€ 49.99$ per year. . .using the recurrent payment model; and a lump-sum amount of $€ 99.83$. . using the single payment model. The implicit discount rate was $100.3 \%$."

The past studies raise a methodological issue in addition to their substantive findings. While most studies kept the cost prompts constant while varying the payment schedules, Kovacs and Larson (2008) and Kim and Haab (2009) adjusted the cost prompts for each payment schedule, using smaller cost prompts with longer payment schedules. That is, the payment schedules were designed, in these two studies, so that a rational individual, using a specified discount rate, would be indifferent between the schedules. This design, while it might seem reasonable intuitively, means that the schedules cannot be used to detect irrational behavior. As an extreme example, consider a survey that compares a $\$ 100$ lump-sum payment versus annual payments of $\$ 23$ for five years, where the $\$ 23$ annual payment was set because it provides the same present value at $8 \%$ as the single $\$ 100$. If the same share of respondents vote yes in each case, the results could mean that (1) respondents are responding rationally to both the bid amount and

9 The authors report (p. 127) that mean WTP is $\$ 57$ per year for respondents offered the ten-year scheme and $\$ 87$ per year for those offered the three-year scheme. At the $4 \%$ discount rate that the authors use and payments starting immediately, PV WTP is $\$ 480$ under the tenyear scheme and $\$ 251$ under the three-year scheme. The implicit discount rate is $39.5 \%$ for this comparison of three-year and ten-year plans. 
the number of payments, using a discount rate of $8 \%$, or (2) respondents are not responding to either the bid amount or the number of payments. ${ }^{10}$ By specifying the bid amounts to reflect rational response, the design makes non-response look the same as rational response. ${ }^{11}$

\section{SURVEY}

We conduct our test using a survey instrument previously used by Myers (2013) and Parsons and Myers (2016). We launched essentially the same survey, but amended the willingness-to-pay questions to test for sensitivity to payment frequency. We used their one-time payment schedule for one of our treatments, and specified an annually recurring payment for our second treatment.

The valuation scenario in our survey is a conservation program designed to protect the Atlantic red knot, a migratory shorebird, which has been in decline for decades. We use an Internet-based survey and sample households in New Jersey and Delaware, a primary stopping point on the red knot's annual migration path. We use Survey Sampling International's opt-in respondent panel and gather data to mimic the New JerseyDelaware (NJ-DE) population along the lines of income, age, and gender. In the final analysis we needed to do some additional weighting of the data to bring the sample in line with actual population characteristics (more on that later).

The survey design follows a common format. We begin with a series of introductory warm-up questions about the environment and migratory birds in the region. Then, we describe the historic and current condition of the red knot using maps, pictures, and graphs. Next, we lay out a hypothetical resource conservation program to be conducted jointly by the states of New Jersey and Delaware to protect the red knot. People were then asked to vote for or against the program at some cost to their

10 Burrows et al. (2016) and Parsons and Myers (2016) provide evidence, in their own and others' studies, of small response to the bid amounts in CV. This chapter suggests that there also exists a small response to the number of payments.

11 Solino et al. (2009) also adjusted their costs prompts. However, their purpose was different, namely, to examine response to payment periodicity when the total amount of payment is the same. They varied the feature in question (periodicity) while holding another feature (total payment) constant, which prevents collinearity. The purpose of the studies by Kovac and Larson (2008) and Kim and Haab (2009) was to examine whether different lengths of payment streams affect the CV estimate of PV WTP under standard discount rates and, equivalently, to estimate the implicit discount rate that reconciles the differences in responses. For this purpose, varying together the number of payments over time and the size of each payment creates collinearity that operates against the goal of estimation. 
household in a referendum-style CV question. Here we use a split-sample survey wherein half of the population sees the program cost as a one-time payment (Version $\mathrm{A}$ ) and the other sees the program cost as a reoccurring annual payment (Version B). In both surveys respondents are shown one of the following bids in a random draw: $\$ 25, \$ 50, \$ 100, \$ 150, \$ 200$, or $\$ 300$. Our null hypothesis is that mean willingness to pay in present value terms is the same in the two samples.

The actual CV referendum question is shown in Figure 1. The wording variation in the one-time versus annual-payment versions of the survey is in square brackets. In addition, in the preamble to the $\mathrm{CV}$ question respondents were told that the upcoming payment frequency would be either one-time or annual. The survey finishes with some auxiliary follow-up questions and the usual set of demographic data. Our sample size is $n=963$ for the one-time payment groups and $n=964$ for the annual recurring group. Table 2 gives demographic information for the two groups.

\section{ANALYSIS}

In Version A of the survey instrument, respondents were asked whether they would be willing to make a one-time payment that would be paid as part of their taxes in 2017. The present value of this payment, at the time that the respondent answered the question, is $P V_{A}=X A /(1+r)$ where $X A$ is the dollar amount of the payment and $r$ is the discount rate, since the taxes will not be paid until a year hence. In Version B, respondents were asked to pay a given amount annually starting in 2017 . The present value is $P V B=X B / r$. The discount rate that equates the present values is $r=X B /$ $(X A-X B) .^{12}$

Table 3 gives the share of "yes" votes at each bid level for both versions of the survey. For each bid, the share is lower for the annual payments than the one-time payment, which indicates a response to the difference in the number of payments. The differences in shares are not statistically significant, but the pattern is uniform.

Table 4 gives (1) the lower-bound (Turnbull) estimate of the mean WTP per payment of each payment frequency, calculated in the usual way (Haab and McConnell, 2002, Ch. 3) with folding back to account for

12 Here is the derivation. Find the $r$ that solves $X A /(1+r)=X B / r$. Rearranging gives $r /(1+r)=X B / X A$. Let $Z=X B / X A$. Rearranging again gives $r=(1+r) Z$ and then $r=Z /$ $(1-Z)$. Substituting $X B / X A$ back into the equation for $Z$ and simplifying gives $r=X B /$ $(X A-X B)$. 
Now, suppose the Red Knot Protection Agreement was on the ballot and that the actions in the Agreement were expected to improve the projected status of the Atlantic red knot in ten years from endangered to stabilized as shown below, and then maintain its stabilized status after ten years

Expected Improvement in the Status of the Atlantic red knot in ten years

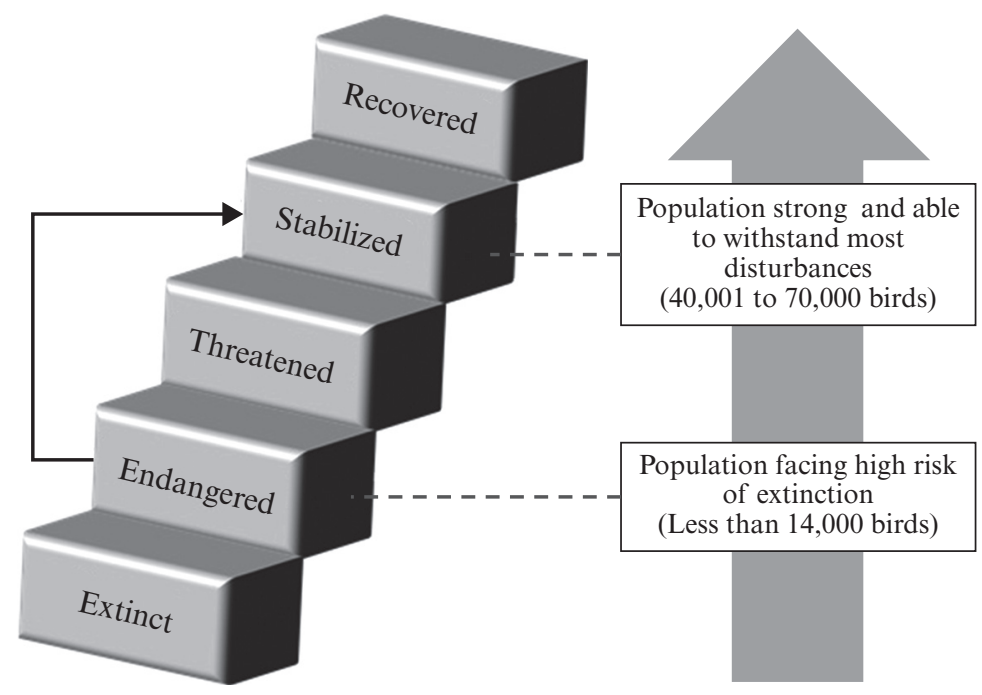

If the total cost to your household to finance the Agreement was [a one-time, or, an annual] payment of $\$[25,50,100,150,200$, or 300$]$ [in 2017, or, starting in 2017], how would you vote if the Agreement were on the ballot in the next election?

Please consider your income, expenses and other possible uses of this money before you vote. Also, please remember that the results of this survey will be provided to policy makers.

O I would vote for the Agreement

I would vote against the Agreement

\section{Figure 1 Referendum question in survey: terms in square brackets varied over respondents}

non-monotonicities; (2) the lower-bound estimate of the mean present value WTP, based on the yield on 30-year Treasury securities of $2.84 \%$ in $2015^{13}$ (which is the yield that Bond et al., 2009 used for their present value calculations, though the yield was 5.49\% in 2009); (3) the implicit discount htm.

13 Accessed November 29, 2016 at http://www.federalreserve.gov/releases/H15/data. 
Table 2 Comparison of split samples

\begin{tabular}{lcc}
\hline & One-time Payment & Annual Payments \\
\hline Number of respondents & 964 & 963 \\
Income group shares & & \\
$<\$ 30,000$ & 19.61 & 19.42 \\
$30,000-50,000$ & 19.29 & 19.31 \\
$50,000-100,000$ & 37.34 & 37.38 \\
$100,000+$ & 23.76 & 23.88 \\
Age group shares & & \\
$18-34$ & 23.86 & 23.88 \\
$35-54$ & 36.31 & 36.14 \\
$55+$ & 39.83 & 39.98 \\
Percentage male & 40.46 & 41.02 \\
Education-level shares & & \\
Some high school or less & 1.45 & 1.14 \\
High school degree & 17.32 & 16.61 \\
Technical school or some college & 21.78 & 25.03 \\
College degree & 34.65 & 35.93 \\
Some graduate work & 5.08 & 5.30 \\
Graduate degree & 19.71 & 15.99 \\
\hline
\end{tabular}

Table 3 Share of yes vote by bid amount

\begin{tabular}{lccccc}
\hline Bid & \multicolumn{2}{c}{ One-time Payment } & & \multicolumn{2}{c}{ Annual Payments } \\
\cline { 2 - 3 } \cline { 5 - 6 } & $\begin{array}{c}\text { Number of } \\
\text { respondents }\end{array}$ & Percentage yes & & $\begin{array}{c}\text { Number of } \\
\text { respondents }\end{array}$ & Percentage yes \\
\hline 25 & 161 & 77.64 & & 161 & 70.81 \\
50 & 161 & 71.43 & & 160 & 69.38 \\
100 & 158 & 70.25 & & 160 & 58.13 \\
150 & 162 & 55.56 & & 161 & 52.17 \\
200 & 160 & 60.63 & & 161 & 50.93 \\
300 & 162 & 49.38 & & 160 & 45.00 \\
\hline
\end{tabular}

rate that equates the present values of the mean WTP per payment for the one-time and annual payments; and (4) $95 \%$ confidence intervals for each of these statistics. The confidence intervals were calculated by the bootstrap method, which explicitly accounts for the random nature of nonmonotonicities in the shares. Confidence intervals are reported instead of standard errors because the bootstrap method does not utilize asymptotic normality. 
Table 4 Turnbull lower-bound estimates (95\% confidence intervals in parentheses)

\begin{tabular}{lcc}
\hline & One-time Payment & Annual Payments \\
\hline WTP per payment & $\$ 179.85$ & $\$ 160.66$ \\
& $(170.09-189.85)$ & $(150.09-171.15)$ \\
Present value of WTP & $\$ 174.88$ & $\$ 5,657.04$ \\
$\quad($ discount rate $=2.84 \%)$ & $(165.39-184.61)$ & $(5,284.86-6,026.41)$ \\
Implicit discount rate & \multicolumn{2}{c}{$837 \%$} \\
& \multicolumn{2}{c}{$(434-3,570 \%)$} \\
\hline
\end{tabular}

With a one-time payment to be made a year after the survey, the lowerbound estimate of the mean WTP is $\$ 180$, which has a present value of $\$ 175$ based on the Treasury yield. With annual payments in perpetuity, the mean WTP for each payment has a lower bound of \$161, giving a present value of $\$ 5,657$. By asking WTP in terms of annual payments instead of a one-time payment, the estimated social value of protecting the red knot rises by a factor of 32 . The implicit discount rate is $837 \%$, under which each passing year reduces the value of a payment by $89 \% .{ }^{14}$ This implicit discount rate is at the higher end of the range found in other studies, but below that in Bond et al. (2009). In any case, it is implausible as a measure of the actual time-value of money to consumers. We also estimated a probit model of the yes/no vote to obtain a parametric estimate of the mean WTP, as opposed to the lower-bound estimate. The results are given in Table 5, with asymptotic standard errors for each statistic. The estimated mean WTP is \$279 for a one-time payment at the end of the year, which translates into a present value of $\$ 271$ at the Treasury yield. As expected, the parametric estimate is higher than the lower-bound estimate. For annual payments, the estimated mean WTP per payment is $\$ 217$, which translates into a present value of $\$ 7,649-$ higher by a factor of 28 . The discount rate implied by the parametric estimates is $351 \%$.

To investigate whether the results are sensitive to various issues, we recalculated the above statistics in the following ways:

14 As discussed above, we define the discount rate in the standard way, under which each year reduces the present value of a payment by $1 /(1+r)$. The discount rate is sometimes defined such that each year reduces the present value of a payment by $(1-d)$. The implicit $r$ of $837 \%$ is equivalent to $d=89 \%$. 
Table 5 Probit estimates (standard errors in parentheses)

\begin{tabular}{lcc}
\hline & One-time Payment & Annual Payments \\
\hline Constant & 0.7337 & 0.5445 \\
& $(0.0764)$ & $(0.0743)$ \\
Cost & -0.002629 & -0.002507 \\
& $(0.000447)$ & $(0.000442)$ \\
WTP per payment & $\$ 279.04$ & $\$ 217.23$ \\
Present value WTP & $(28.02)$ & $(21.30)$ \\
& $\$ 271.33$ & $(750.00)$ \\
Implicit discount rate & $(27.26)$ & $351 \%$ \\
& \multicolumn{3}{c}{$(222 \%)$} \\
\hline
\end{tabular}

- Census weights: Using weights for respondents such that the weighted sample reflects the US census shares by age, income group, and gender. ${ }^{15}$

- Certainty weights: Using weights that account for each respondent's level of certainty about their yes/no vote. In a follow-up question, each respondent was asked to give, on a slider-scale between 1 and 10 , their level of certainty in their vote. We created weights that are proportional to level of certainty and sum to sample size.

- Uncertainty elimination: Using only those respondents whose level of certainty was 7 or higher. This requirement eliminated 402 respondents, with the analysis performed on the remaining 1,525, of whom 984 voted yes.

- Elimination based on disbelief of cost: In a follow-up question, respondents were asked whether they believed, if the measure passed, they would actually be charged the amount that they had been told. The 737 respondents who indicated that they thought that they would pay a different amount (either higher or lower) were omitted, and the analysis was conducted on the remaining 1,190 respondents, of whom 760 voted yes.

Table 6 gives the point estimates for each statistic; confidence intervals and standard errors are available on request from the authors. The findings are essentially the same as those shown in Tables 4 and 5: the estimated

15 As noted above, Survey Sampling International (SSI) generated a sample as close as possible to the population along these lines. However, due to limits in their pool of respondents in certain cells, their outcomes missed the population proportions. This correction brings the sample in line with the population. 
Table 6 Sensitivity results

\begin{tabular}{lccccc}
\hline & Baseline & $\begin{array}{c}\text { Census } \\
\text { Weights }\end{array}$ & $\begin{array}{c}\text { Certainty } \\
\text { Weights }\end{array}$ & $\begin{array}{c}\text { Uncertainty } \\
\text { Elimination }\end{array}$ & $\begin{array}{c}\text { Cost } \\
\text { Disbelief } \\
\text { Elimination }\end{array}$ \\
\hline $\begin{array}{l}\text { Lower-bound estimates } \\
\text { One-time payment (\$): }\end{array}$ & 179.85 & 191.06 & 182.45 & 188.76 & 183.64 \\
$\quad$ WTP & 174.88 & 185.78 & 177.41 & 183.55 & 178.57 \\
$\quad$ PV WTP & & & & & \\
Annual payments (\$): & 160.66 & 167.00 & 162.67 & 169.24 & 165.19 \\
$\quad$ WTP per payment & $5,657.04$ & $5,880.28$ & $5,727.82$ & $5,959.16$ & $5,816.55$ \\
$\quad$ PV WTP & 837 & 694 & 822 & 867 & 895 \\
Implicit discount rate (\%) & & & & & \\
Parametric estimates & & & & & \\
One-time payment (\$): & 279.04 & 331.41 & 279.15 & 298.67 & 270.51 \\
$\quad$ WTP & 271.33 & 322.26 & 271.44 & 290.42 & 263.04 \\
$\quad$ PV WTP & & & & & \\
Annual payments (\$): & 217.23 & 249.29 & 217.09 & 230.25 & 217.89 \\
$\quad$ WTP per payment & $7,648.94$ & $8,777.82$ & $7,644.01$ & $8,107.39$ & $7,672.18$ \\
$\quad$ PV WTP & 351 & 304 & 350 & 337 & 414 \\
Implicit discount rate (\%) & 351 & & & & \\
\hline
\end{tabular}

present value at the Treasury yield is far greater when the survey asks about annual payments than a one-time payment, and the implicit discount rate is implausibly large.

\section{CONCLUSIONS}

One would expect and certainly hope for validity purposes that WTP response data would be sensitive to the frequency of payment in a referendum-style CV question. In our application, we found little sensitivity to payment frequency when comparing one-time with annual reoccurring payments. Our finding is consistent with the literature investigating such effects. Given respondents' inattention to the detail of payment frequency (essentially treating them as the same), the implied PV WTP is substantially larger with annual reoccurring payments versus one-time payments in all cases. Indeed, in other studies, as the payment frequency increases, so does the implied WTP. It is not possible to discern from our study or the other studies whether one of the payment frequencies leads to a "truer" WTP. More likely, in our judgment, respondents are either or both using the referendum as a means to convey support for the shorebird and not treating the tax as an actual payment or they have little idea of what their 
actual WTP is and are anchoring on the values offered. Whatever the cause, care must be taken in using CV response data as it pertains to payment frequency. Using one-time versus annual reoccurring payments can swing benefit estimates by as much as a factor of 30 and for reasons at this time we really do not understand. Further research documenting and exploring the effect of payment frequency and perhaps follow-up questions on the issue would be useful given the limited evidence we have to date.

\section{REFERENCES}

Bond, C., K. Cullen, and D. Larson (2009), "Joint estimation of discount rates and willingness to pay for public goods," Ecological Economics, 68(11), 2,751-59.

Boyle, K. (forthcoming), "Contingent valuation in practice," in P. Champ, K. Boyle, and T. Brown (eds), A Primer on Nonmarket Valuation, New York: Springer.

Burrows, J., H.-M. Chan, and P. Dixon (2016), "Response to cost prompts in stated preference valuation of environmental goods," in D. McFadden and K. Train (eds), Contingent Valuation of Environmental Goods: A Comprehensive Critique, Cheltenham, UK and Northampton, MA, USA: Edward Elgar Publishing.

Chen, W., J. Aertsens, I. Liekens, S. Broekx, and L. Nocker (2014), "Impact of perceived importance of ecosystem services and stated financial constraints on willingness to pay for riparian meadow restoration in Flanders (Belgium)," Environmental Management, 54(2), 346-59.

Echeverria, J., M. Hanrahan, and R. Solorzano (1995), "Valuation of non-priced amenities provided by the biological resources within the Monteverde Cloud Forest Preserve, Costa Rica," Ecological Economics, 13(1), 43-52.

Egan, K., J. Corrigan, and D. Dwyer (2015), "Three reasons to use annual payments in contingent valuation surveys: Convergent validity, discount rates, and mental accounting," Journal of Environmental Economics and Management, 72, 123-36.

Haab, T. and K. McConnell (2002), Valuing Environmental and Natural Resources: The Econometrics of Non-Market Valuation, Cheltenham, UK and Northampton, MA, USA: Edward Elgar Publishing.

Kahneman, D. and J. Knetsch (1992), "Valuing public goods: The purchase of moral satisfaction," Journal of Environmental Economics and Management, 22(1), 57-70.

Kim, S.I. and T. Haab (2009), "Temporal insensitivity of willingness to pay and implied discount rates," Resource and Energy Economics, 31(2), 89-102.

Kovacs, K. and D. Larson (2008), "Identifying individual discount rates and valuing public open space with stated-preference models," Land Economics, 84(2), 209-24.

Myers, K. (2013), 'The effect of substitutes on willingness to pay for endangered species: The case of the Atlantic red knot', PhD thesis, School of Marine Science \& Policy, University of Delaware, Publication No. 3613043 at ProQuest Dissertations and Theses.

Parsons, G. and K. Myers (2016), "Fat tails and truncated bids in contingent valuation: An application to an endangered shorebird species," Ecological Economics, 129, 201-19. 
Rowe, R., W. Shaw, and W. Schulze (1992), "Nestucca oil spill," in K. Ward and J. Duffield (eds), Natural Resource Damages: Law and Economics, New York: John Wiley, pp. 527-54.

Solino, M., M. Vazquez, and A. Prada (2009), "Social demand for electricity from forest biomass in Spain: Does payment periodicity affect the willingness to pay?," Energy Policy, 37(2), 531-40.

Stevens, T., N. DeCoteau, and C. Willis (1997), "Sensitivity of contingent valuation to alternative payment schedules," Land Economics, 73(1), 140-48.

Strumberg, B., K. Barenklau, and R. Bishop (2001), "Nonpoint source pollution and present values: A contingent valuation study of Lake Mendota," Review of Agricultural Economics, 23(1), 120-32. 